\title{
Model Studies of Composite Building Frame Behaviour in Fire
}

\author{
J. A. EL-RIMAW] \\ Department of Civil Engineering, Loughborough University of Technology, \\ Loughborough, United Kingdom.
}

I. W. BURGESS

Department of Civil and Structural Engineering

R. J. PLANK

School of Architectural Studies, University of Sheffield, Western Bank, Sheffield S10 2TN, United Kingdom.

\begin{abstract}
A series of analytical studies is presented on the behaviour of an unprotected plane composite steel-concrete frame under fire scenarios which occur across single storeys of the structure. The main purpose is to assess the effectiveness of using various types of sub-assembly in predicting the structural behaviour in fire. The studies are based on modelling a full-scale experimental multi-storey frame in which some fire testing is to take place shortly, and in part originate from a programme of analyses in which the authors have participated whose aim has been to determine the test parameters required. For the basic modelling studies the frames and subframes are assumed to be rigidly connected, but the effect of the semi-rigidity of real connections is also investigated. The analyses are all performed using a program NARR2, whose most recent development has been the capability to take into account strain reversal whenever it happens. This allows an assessment of the residual effects on the frame members after a local fire has been extinguished and the frame has returned to ambient temperature.
\end{abstract}

KEYWORDS: Fire, Steel Structures, Frames, Connections.

\section{INTRODUCTION}

Building regulations require that the structural integrity of a building is maintained for a specified period in the event of a fire. Design codes for structural steelwork have traditionally adopted a prescriptive approach for determining fire protection requirements, although more recently some calculation methods $[1,2]$ have been introduced for estimating fire resistance. These are generally concerned with isolated elements and are based mainly on the results of experimental studies. Large-scale structures are rarely fire tested because of cost and the physical limitations of standard furnaces. Hence there is little experimental evidence relating the fire resistance of individual members to that of a complete building frame assembly, even though there are indications that continuity between adjacent elements may significantly influence fire survival. A way of overcoming size limits on testing is the use of numerical 
simulation. There has therefore been much interest in the development of computer programs which model the behaviour of structural frames and sub-assemblies in fire.

When a new field of computer modelling begins to expand it is important that the process of validation is treated with some care, especially where there is no body of knowledge generated by testing and previous analytical methods. In the United Kingdom this has for some years been a concern, in the context of structural behaviour in fire, of an open modelling group involving academics from several universities together with researchers from industry and research institutes. The group has provided a forum in which both thermal and structural aspects of modelling have been discussed, enabling techniques to be refined on several fronts. The results of furnace test programmes have been made available for comparison, and it has even been possible to design tests on individual elements in ways which avoid incompatibility with the simulations. In the most recent phase of its activities the group has collaborated in a programme of initial analyses aimed at designing a series of natural fire tests, which are scheduled to begin in 1994, on a full-scale multi-storey frame. This has been constructed by the Building Research Establishment in its large-scale testing facility at Cardington. A series of ambient-temperature static and dynamic tests will precede the fire tests. The whole test sequence could provide a store of data which will be very valuable in gauging the performance of complete buildings against design and analytical models. In the case of fire performance in particular this is a unique opportunity.

Prediction of the structural response of building frames to fire involves a series of highly iterative non-linear calculations at different temperatures, and analysing extensive frames is often very time consuming. In practice, fires are often localised by compartmentation to stay within certain areas of a building, and this poses the question of whether a study of the complete frame is really necessary. The use of limited subframes has long been accepted as sufficiently accurate for structural analysis in ambient-temperature design, but little has been done to investigate the validity of this type of simplified model in analysis for fire engineering.

In practice, multi-storey frames are usually designed as braced and as statically determinate, in the sense that beams are analysed as if they were simply-supported and columns are assumed to be loaded only by beam end-reactions which may act eccentrically, creating moments. It is now well known that beam-to-column connections designed for these assumptions actually have stiffness and strength which may enhance the structural performance, particularly in fire conditions when the supported beams lose stiffness to a great extent. Studies[3] on the characteristics of such connections at ambient temperature, a limited test programme at elevated temperature [4], and some previous analyses [5] have indicated that they may have an important contribution to make towards fire survival of the building, particularly in local fires.

This paper compares the effectiveness of analysing different two-dimensional sub-assemblies predicting the behaviour in fire of a full plane composite frame. This comparison includes deflections, internal forces and limiting temperatures. As a context for the studies a section through the Cardington frame has been used. Both rigid and semi-rigid beam-column connections are included. The analyses have all used the program NARR2[6].

\section{THE CARDINGTON TEST FRAME}

The frame has been designed to be as representative of typical commercial multi-storey construction as possible. It is an 8-storey $\times$ 5-bay frame, with lightweight concrete floor slabs on profiled metal decking, connected through shear connectors to the upper flanges of steel 
beam sections forming composite beams. The frame is 3 bays deep, with outer spans of $6 \mathrm{~m}$ and a middle span of $9 \mathrm{~m}$, and a typical storey height of $4.185 \mathrm{~m}$. The plane frame in which the present fire scenarios are assumed to take place is depicted in Fig. 1.

The columns are orientated to bend about their major axes for the frame shown. The main beams have been designed to a stringent deflection criterion, and as a result of this the utilisation factor (actual design bending moment as a proportion of the bending capacity) is rather low, particularly for the $9 \mathrm{~m}$ span inner beams; these frames repeat at $9 \mathrm{~m}$ centres. The floor slab spans $3 \mathrm{~m}$ between secondary beams which are also composite. These are supported on the main beams which are connected to the steel columns by flush end plates. A central atrium, two service shafts and other ancillary facilities are accommodated by local variations from this form. The building is clad, but is largely free from internal partitions. In addition to the dead loads present, typical office loading will in general be simulated using water tanks over the whole usable floor area. This imposed load intensity has been set at $1.17 \mathrm{kN} / \mathrm{m}^{2}$, about a third of the design imposed load, and is based on observation of actual office loadings. However, it is possible to apply different loadings, particularly if these are limited in extent.

In addition to basic tests on the structure, both during construction and after completion, a series of tests is planned on static and dynamic behaviour. On completion of these tests, which will be non-destructive, fire and explosive testing programmes will be undertaken. This paper is concerned with the fire tests, which will be expensive, and hence limited in extent. They are therefore being carefully designed to ensure maximum advantage. This involves decisions about the parts of the structure to be heated; the temperature regime required and its practicability; the measurements to be made during the test (deflections, strains, forces,

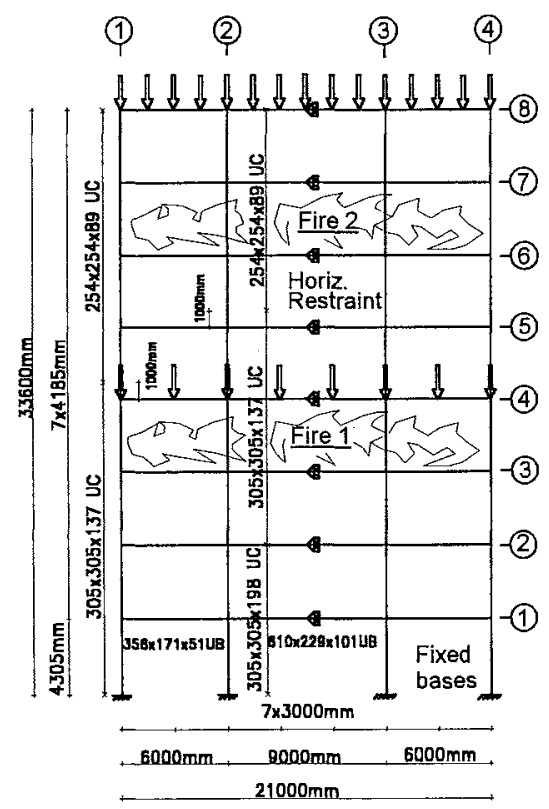

\begin{tabular}{|l|l||c|c|c|}
\hline \multicolumn{2}{|l|}{ Positions } & $\begin{array}{l}\text { Hot } \\
\text { flange }\end{array}$ & Web & $\begin{array}{l}\text { Cold } \\
\text { flange }\end{array}$ \\
\hline \hline \multirow{3}{*}{$\begin{array}{l}\text { Outer } \\
\text { column }\end{array}$} & Lower & 0.5 & 0.4 & 0.3 \\
\cline { 2 - 5 } $\begin{array}{l}\text { Inner } \\
\text { column }\end{array}$ & Lower & 1.0 & 0.8 & 0.6 \\
\cline { 2 - 5 } $\begin{array}{l}\text { Outer } \\
\text { beam }\end{array}$ & Upper & 1.0 & 1.0 & 1.0 \\
\cline { 2 - 5 } & Slab & & & 0.2 \\
\cline { 2 - 5 } & Joint & 0.7 & & \\
\cline { 2 - 5 } & Edges & 0.9 & 0.8 & 0.7 \\
\hline \multirow{3}{*}{$\begin{array}{l}\text { Inner } \\
\text { beam }\end{array}$} & Slab & 1.0 & 1.0 & 0.8 \\
\cline { 2 - 5 } & Joint & 0.2 & & 0.2 \\
\cline { 2 - 5 } & Edges & 0.8 & 0.7 & 0.6 \\
\cline { 2 - 5 } & Middle & 0.9 & 0.9 & 0.7 \\
\hline \hline
\end{tabular}

FIGURE 1. Section through the Cardington frame, including fire compartments studied. Also key element temperatures as proportions of reference temperature. 
temperatures etc.); and the structural conditions, particularly the load level. There is clearly an important connection between test load and the failure temperature. A number of researchers from various centres, including the present authors, are conducting studies of how these are related, and some of the results reported here have been generated as part of this effort.

Although a number of different fire tests are under consideration, at present attention is being focused on those (shown in Fig. 1) which most closely follow the structural engineer's representation of the building, using a plane frame through the structure with two fire compartments. The test arrangement avoids as far as possible non-typical areas, such as those adjacent to service shafts and the atrium, as well as column splices.

\section{MODEL STUDIES}

In the initial analyses the full plane frame was analysed, assuming fully rigid joints. This assumption may seem paradoxical, since the individual members are designed as simply supported. However, it may be justified on two grounds:

(i) Simple connections in non-composite steel frames are always observed to heat in a fire more slowly than the beams to which they are attached. The rotational stiffness of a beamcolumn connection therefore increases relative to that of the beam it supports, although it deteriorates in absolute terms, and the end conditions move towards fully-fixed. This is supported by previous studies[5] on non-composite frames.

(ii) The beams are fully composite in the present case, and the in-situ concrete slab continues over the whole floor area. It contains a light reinforcing mesh which gives some continuity across beam-column connections. This produces, at ambient temperatures, a connection with a large lever arm which is much stiffer than the end-plate connection between the steel sections, but without a great deal of rotation capacity. In fire the effect of embedment in the concrete is to keep the mesh almost at ambient temperature throughout, so that the only deterioration is at the steel-to-steel connection below the slab.

Two different fire locations were considered, which will be referred to as Levels 4 and 7 (the numbering refers to the beam level directly above the fire). Fixed temperature relationships within the key parts of the structural elements in the fire compartment were assumed, and these are tabulated on Fig. 1. They are based on temperature distributions which have been observed in previous tests on individual elements and limited assemblies[7,8]. The reference temperature for all of these was taken as that in the bottom flange of the primary steel beam at mid-span - it has been observed that temperatures reduce from this towards the ends of beams, in unprotected columns and in key elements of connections. Temperatures in parts of the structure outside the compartment were assumed to remain at $20^{\circ} \mathrm{C}$. This form of temperature pattern means that no specific time-temperature relationship is needed, and results can therefore be presented relative to the reference temperature rather than to time

The degradation in steel strength characteristics with temperature was assumed to follow the EC3 relationships[2], with the small amendment of a post-yield tangent modulus of $1 / 100$ of the appropriate high-temperature initial elastic modulus. Nominal section dimensions and ambient-temperature material properties were assumed. The beams were treated as fully composite, with an effective concrete flange width equal to a quarter of the span. The cylinder strength of the concrete was assumed to be $35 \mathrm{~N} / \mathrm{mm}^{2}$, varying with temperature in accordance with EC4[9], and its tensile strength was ignored. 


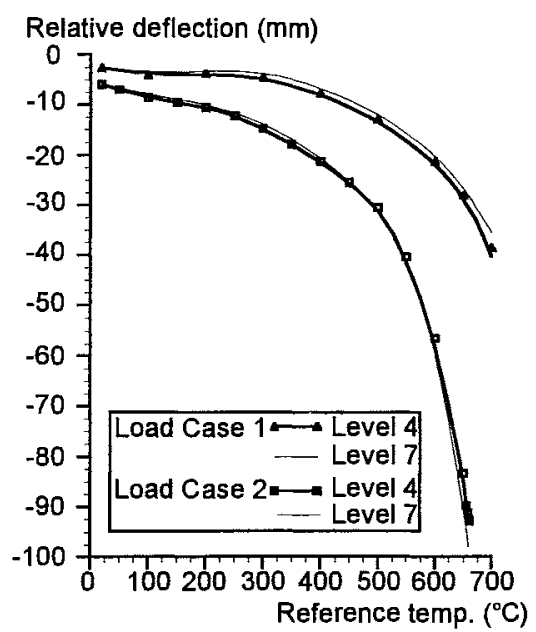

(a)

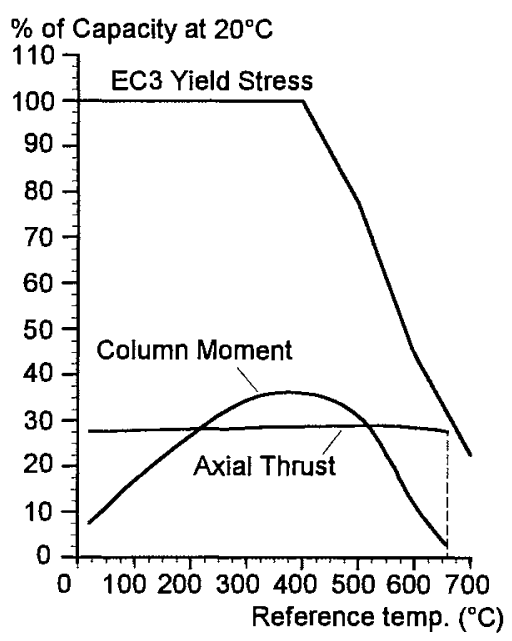

(b)

FIGURE 2. (a) Vertical relative deflection for mid-span points of the outer beam spans under fires at Levels 4 and 7. Full-frame analysis with rigid connections. (b) Inner column forces as proportion of ambient-temperature capacity as temperature increases.

It is not always obvious what constitutes "failure" when only part of a structure is heated, and sensible criteria have to be set. In this case the analysis was continued until the occurrence either of excessive beam deflections (indicated by the relative deflection exceeding span/20), or of column failure due to instability or yield. Initially the analysis was performed at set temperature increments, but in the failure region a bisection process was implemented to ensure convergence to within $\pm 5^{\circ} \mathrm{C}$.

For each of the levels two different loading conditions were considered. In Load Case 1 the nominal frame loading (total load intensity of $4.82 \mathrm{kN} / \mathrm{m}^{2}$ ) was assumed to be applied throughout. In Load Case 2 the same nominal loading was applied generally, but with increased loads corresponding to the maximum loading (of $10.7 \mathrm{kN} / \mathrm{m}^{2}$ ) which might practically be applied in a non-destructive test, on the heated beams. These loads are, of course, actually applied to the primary beams by the secondary beams at $3 \mathrm{~m}$ centres.

\section{Full-Frame Analyses}

Results of full-frame analyses are plotted in Fig. 2 for fires at Levels 4 and 7, showing midspan deflections versus reference temperatures for the more critical outer beam. The deflections are calculated relative to the joints at the beam ends. These indicate behaviour typical of single-span beams, with an initial gradual increase in deflection largely due to thermal bowing, followed by a more rapid increase in deformation as the beam accelerates its loss of bending stiffness and strength. Whereas the analysis of a simple beam is normally limited by the deflection criterion, in this case the maximum relative deflection attained was relatively small. In fact, a study of the stresses in the columns suggests that failure was 
precipitated predominantly by yielding of the column. To illustrate this Fig. 2(b) shows the change of bending moment and axial thrust at the top of one of the inner columns just below the critical beam level as the temperature increases, as proportions of the corresponding capacities at ambient temperature. It also shows the proportional reduction of yield stress with temperature. It is clear that at failure the bending moment has almost vanished whilst the axial thrust is very close to the high-temperature squash value.

For Load Case 1, the failure temperatures are approximately $680^{\circ} \mathrm{C}$ for the Level 4 fire and $750^{\circ} \mathrm{C}$ for Level 7 - rather higher than the limiting temperatures for single elements. There are two principal factors affecting this - the rigidity of connections and the relatively low load ratios in the steel members. For Load Case 2 the pattern is similar, but failure temperatures reduce to approximately $660^{\circ} \mathrm{C}$ for both levels. Although the more pronounced reduction in failure temperature for Level 7 may seem surprising, it should be recognised that the proportionate increase in column load at this level is much greater than for Level 4. Because the failure is dominated by yielding in the columns, this is reflected in the failure temperatures.

These results may have implications for the proposed tests. The failure temperatures for Load Case 1 are higher than the proposed heating system can generate within a reasonable time. The lower failure temperatures for Load Case 2 are easier to achieve. Although the nominal frame loads represent real loading conditions, they are significantly lower than design loads. Since an objective of the tests is to validate the software for generating design data, it is desirable for the loadings to represent the strength limit state rather than normal occupancy loads. This reinforces the case for using full unfactored design loads on the test floors.

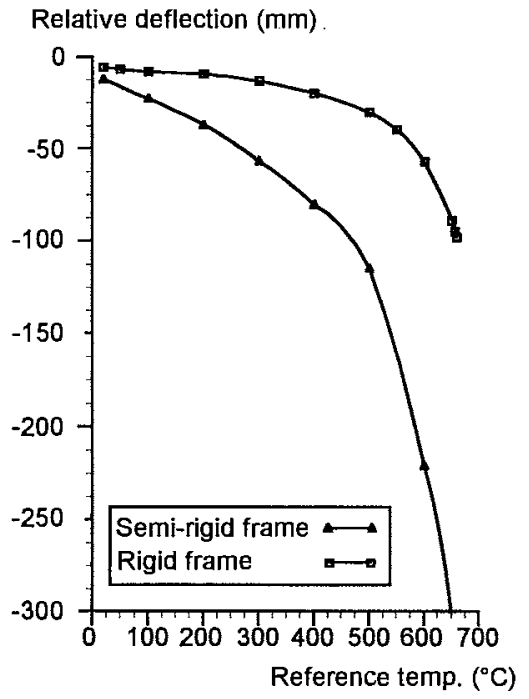

(a)

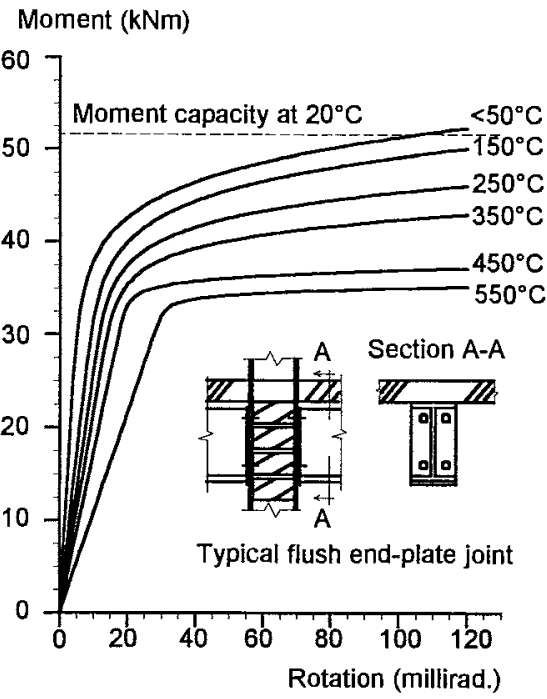

(b)

FIGURE 3. (a) Comparison between vertical relative deflections at mid-span of outer beams for Level 4, Load Case 2 fire, assuming rigid and semi-rigid connections. (b) The postulated moment-rotation-temperature curves for a flush end-plate connection. 
The above results are based on the assumption of fully rigid connections. As has been stated, the composite beam-column connections have finite rigidity, although little experimental data exists on the moment-rotation characteristics or their deterioration in fire. However, based on a limited high-temperature experimental study[4] on non-composite connections, and the greater body of data available for ambient temperature behaviour[3], moment-rotationtemperature relationships have been postulated[10] for non-composite connections. An example of this connection model is shown in Fig. 3(b). In order to establish the sensitivity of the frame behaviour to these characteristics, the analyses were repeated with semi-rigid connections. It should be noted that the connections assumed here are not based on the actual composite arrangement which includes a mesh in the slab, but simply on a scaling of the endplate curves shown with respect to the beam depths. The effect of connection stiffness is therefore considerably understated in these analyses.

The results are shown in Fig. 3(a) for Load Case 2, Level 4. The amount of beam deformation is clearly greatly increased for the semi-rigid condition. However, the failure temperatures show little difference, and again this may be because failure is largely due to column softening rather than to excessive beam deformation. This suggests that for this particular frame the precise representation of connection stiffness is relatively unimportant, although this conclusion could certainly not be applied to all frame configurations.

\section{Subframe Analyses}

The analysis of subframes rather than complete structures is attractive since it has the potential to reduce computation time dramatically, which could be of significance if large numbers of results need to be generated for design documents. A study was therefore conducted to establish how accurate such representations might be. The series of subframes shown in Fig. 4 was considered. These are typical of those specified in design codes[11] for approximate analysis of the structural behaviour of individual elements within a rigid frame. They can be categorised as beam or column subframes, and were initially assumed to be rigidly connected. Individual simply supported and built-in beams were also considered, as bounding cases.

The results of the subframe analyses are compared with full-frame analyses in Fig. 5. These are shown as relative deflections at mid-span of the outer beam for Load Case ?, Level 4. For this example there is clearly generally good agreement between subframe and full frame results, for both beam and column subframes. However the results for Subframe 4, which does not include the critical inner column, suggest that failure is dominated by beam deformation rather than by column softening, which is clearly incorrect. The fact that critical temperatures in the right region have here been obtained from the wrong behaviour provides a necessary warning about the use of subframes - if the choice of subframes is illogical then there may be no way in which the behaviour of some elements can be examined properly.

The comparisons have been re-run using semi-rigid connections, and the results are shown on Fig. 5. Once again sensible subframe representations give very close predictions for the failure temperature calculated from full-frame analysis. The deformation histories of the equivalent simply supported and fixed-ended beams are also shown for comparison with the frame and subframe results. In this case a fixed-ended beam predicts well the behaviour of a beam within a rigid frame, up to the temperature at which the column precipitated failure, but if viewed in isolation its failure temperature would be misleadingly high. Predictably the simply supported beam underestimates the failure temperatures fairly considerably. 


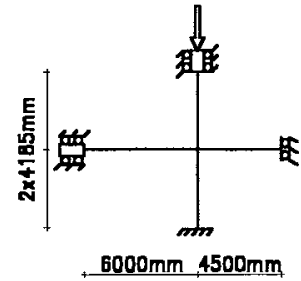

Subframe 1 (Inner beam)

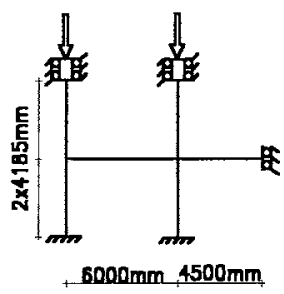

2 (Outer beam)

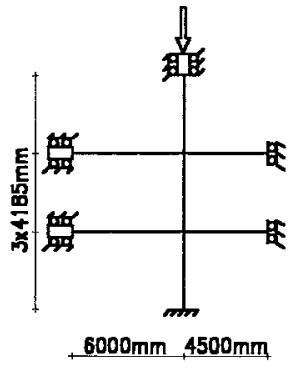

3 (Inner column)

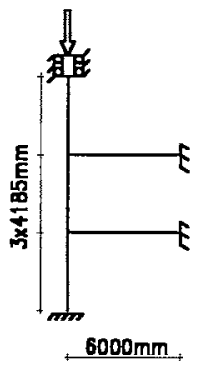

4 (Outer column)

FIGURE 4. Beam and column subframes used to conduct the subframe analyses, based on those used at ambient temperature for design calculations.

A complete summary of the failure temperatures calculated using these different representations is given in Table 1. This includes comparisons with failure temperatures calculated in accordance with design code procedures. These results suggest that subframes may give sufficiently good predictions, although care is needed in selecting the representation used. The results for simple beam representations are, however, not reliable, and clearly the codified values are least accurate in comparison with the full frame results.

These comparisons are only indicative, and more comprehensive study is needed on a wider range of cases before definitive conclusions can be drawn. The tables are also only concerned with failure temperatures. Other aspects of the behaviour may be critically dependent on the structural and boundary conditions assumed in the analysis. One of the more sensitive of these aspects is the axial thrust generated in beams, as may be seen from Fig. 6, in which axial forces in the two beams considered are compared for the full-frame and subframe cases. The degree of axial restraint to thermal expansion provided by the boundary conditions and subframe configuration clearly has a considerable effect.

In the context of the proposed full scale frame tests, the comparisons indicate that in refining the test details a series of subframe analyses should be sufficiently accurate, particularly in view of the other inevitable uncertainties associated with such testing. By implication, the results also suggest that a local change in load level, altering the load ratios in the heated elements only, is likely to be representative of how the structure would respond to a universal change in load, although of course column load ratios are relatively little affected by a local load increase.

\section{Indicative Studies}

Two further indicative studies have been conducted. The first is concerned with reducing the influence of column softening, by repeating the analyses with the column temperatures maintained at $20^{\circ} \mathrm{C}$. This is prompted by the typical architect's desire to encase steel columns to present a more acceptable shape within open-plan space, which can often make at least this degree of retrospective fire-protection inevitable. The results are not shown here, but in all cases the failure is characterised by excessive beam deflections in the outer beam. Failure 
TABLE 1. Summary of results of the main Cardington frame analyses undertaken.

\begin{tabular}{|c|c|c|c|c|c|c|}
\hline Description & $\begin{array}{l}\text { Fire } \\
\text { Level }\end{array}$ & $\begin{array}{l}\text { Load } \\
\text { Case }\end{array}$ & $\begin{array}{c}\text { Subframe } \\
\text { No. }\end{array}$ & $\begin{array}{c}\text { Outer } \\
\text { span/20 }\end{array}$ & $\begin{array}{c}\text { Inner } \\
\text { span/20 }\end{array}$ & Maximum \\
\hline \multirow{2}{*}{$\begin{array}{l}\text { BS5950 Pt8 limiting } \\
\text { temperatures for beams }\end{array}$} & \multirow[t]{2}{*}{ Any } & \multirow[t]{2}{*}{2} & $\mathrm{~S} / \mathrm{S}$ beam & $590^{\circ} \mathrm{C}$ & $657^{\circ} \mathrm{C}$ & - \\
\hline & & & Fixed beam & $666^{\circ} \mathrm{C}$ & $766^{\circ} \mathrm{C}$ & - \\
\hline \multirow{2}{*}{$\begin{array}{l}\text { EC3 Pt10 limiting } \\
\text { temperatures for beams }\end{array}$} & \multirow[t]{2}{*}{ Any } & \multirow[t]{2}{*}{2} & $\mathrm{~S} / \mathrm{S}$ beam & $560^{\circ} \mathrm{C}$ & $629^{\circ} \mathrm{C}$ & - \\
\hline & & & Fixed beam & $639^{\circ} \mathrm{C}$ & $734^{\circ} \mathrm{C}$ & - \\
\hline \multirow[t]{2}{*}{ Rigid full frame } & \multirow[t]{2}{*}{7} & 1 & Full & - & - & $750^{\circ} \mathrm{C}$ \\
\hline & & 2 & Full & - & - & $661^{\circ} \mathrm{C}$ \\
\hline \multirow[t]{2}{*}{ Rigid full frame } & \multirow[t]{2}{*}{4} & 1 & Full & - & - & $700^{\circ} \mathrm{C}$ \\
\hline & & 2 & Full & - & - & $659^{\circ} \mathrm{C}$ \\
\hline Semi-rigid frame & & 2 & Full & $650^{\circ} \mathrm{C}$ & $733^{\circ} \mathrm{C}$ & $\sim 800^{\circ} \mathrm{C}$ \\
\hline \multirow{4}{*}{$\begin{array}{l}\text { Rigid connections, } \\
\text { heated as full frame. }\end{array}$} & \multirow[t]{4}{*}{4} & \multirow[t]{4}{*}{2} & 1 & - & - & $669^{\circ} \mathrm{C}$ \\
\hline & & & 2 & - & - & $667^{\circ} \mathrm{C}$ \\
\hline & & & 3 & - & - & $670^{\circ} \mathrm{C}$ \\
\hline & & & 4 & $727^{\circ} \mathrm{C}$ & - & $-750^{\circ} \mathrm{C}$ \\
\hline \multirow{2}{*}{$\begin{array}{l}\text { Semi-rigid connections, } \\
\text { heated as full frame. }\end{array}$} & \multirow[t]{2}{*}{4} & \multirow[t]{2}{*}{2} & 1 & $640^{\circ} \mathrm{C}$ & - & $\sim 700^{\circ} \mathrm{C}$ \\
\hline & & & 2 & $650^{\circ} \mathrm{C}$ & $713^{\circ} \mathrm{C}$ & $\sim 750^{\circ} \mathrm{C}$ \\
\hline \multirow{4}{*}{$\begin{array}{l}\text { Rigid connections, } \\
\text { columns NOT heated. }\end{array}$} & \multirow[t]{4}{*}{4} & \multirow[t]{4}{*}{2} & 1 & $740^{\circ} \mathrm{C}$ & - & $\sim 800^{\circ} \mathrm{C}$ \\
\hline & & & 2 & $753^{\circ} \mathrm{C}$ & - & $\sim 800^{\circ} \mathrm{C}$ \\
\hline & & & 3 & $730^{\circ} \mathrm{C}$ & & $\sim 800^{\circ} \mathrm{C}$ \\
\hline & & & 4 & $753^{\circ} \mathrm{C}$ & - & $-800^{\circ} \mathrm{C}$ \\
\hline
\end{tabular}

Relative deflection ( $\mathrm{mm}$ )

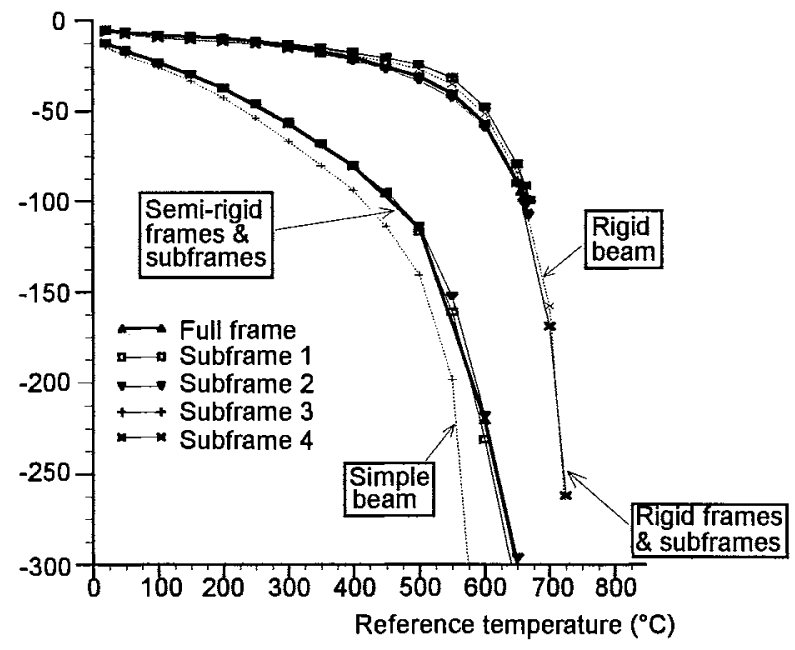

FIGURE 5. Comparison of outer-span beam relative deflections for Level 4, Load Case 2 fire. Cases shown are rigid and semi-rigid full-frame and subframe analyses, together with the equivalent simply supported and fixed-ended single-span beams. 
temperatures were approximately $740^{\circ} \mathrm{C}$, and it is evident that the different subframe representations produce very consistent results.

The analytical method which has been used to perform these studies has recently been extended to allow for the effects of plastic strain reversal. The program NARR2 has been developed to account for this effect, which will occur widely during the cooling-down phase of a natural fire. The ability to include the material 'unloading' characteristics will enable the prediction of permanent deformations and residual forces resulting from a fire. To illustrate the possible residual effects after a local fire, the full frame was re-analysed for the Level 4 fire under Load Case 2. The reference temperature was raised in $50^{\circ} \mathrm{C}$ increments to $650^{\circ} \mathrm{C}$, with all other temperatures maintaining their normal relationships. The reference temperature was then allowed to fall at the same rate to ambient temperature, with all temperatures still maintaining their fixed relationships. This is clearly only a schematic representation of the temperature variations during a natural fire, but the results indicate the effects which may be expected in a fire-affected building. Fig. 7 plots the change of internal forces and deflections with change of reference temperature. It also shows the major residual effects after this fire scenario, including the zones of the frame which have developed some degree of permanent strain. This type of information could be of great significance in the aftermath of a building fire, since it is an indication of the members which should be replaced during repair of the structure, and of the re-usability of the building. It can be seen in this case that the heated beams and a large portion of the heated columns have developed permanent strains; these also exist in small zones of the columns above the heated floor level. In the figure no indication has been given of the magnitude of such strains. This is the subject of a current research study, and the results will be published in due course.

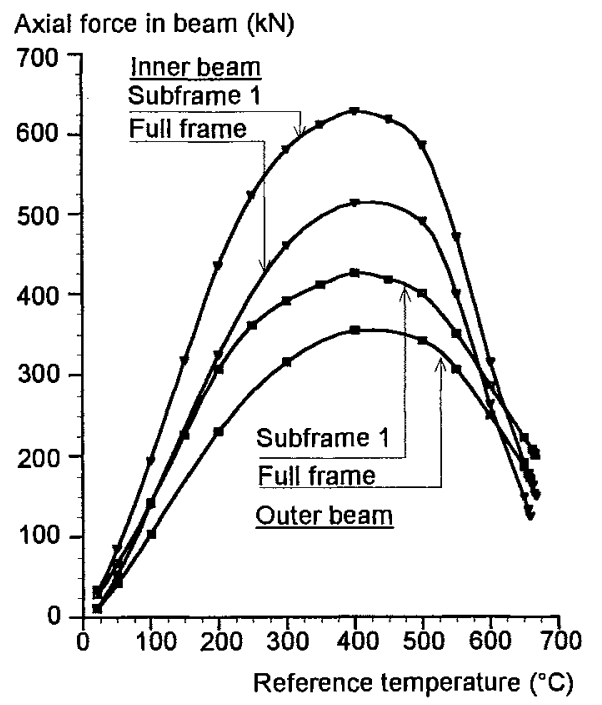

FIGURE 6. Effect of the stiffness of adjacent structure on the development of axial thrust in beams, for Level 4 , Load Case 2 fire. 


\section{Bending Moments}

5

4

3

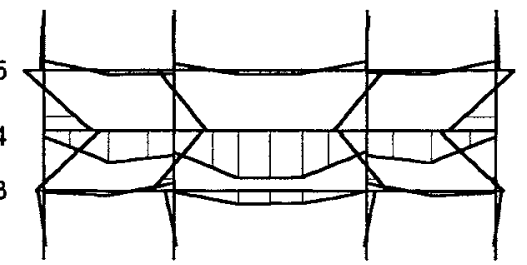

\section{Deflected Shape}

5

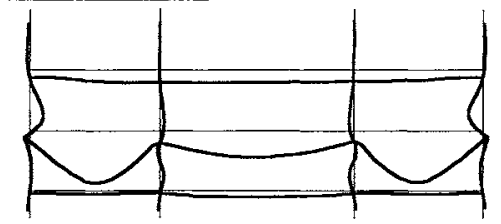

Yielded Zones

5

4

3

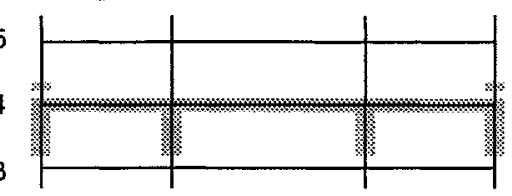

Total deflection $(\mathrm{mm})$

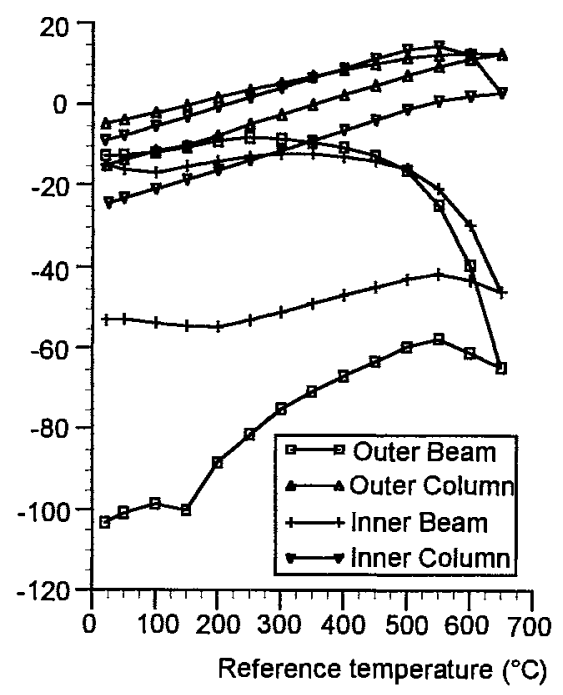

FIGURE 7. Residual effects (bending moments, deformed shape and permanently strained zones) after cooling of the Level 4, Load Case 2 fire. The development of deflections with fire growth and decay is also shown.

\section{CONCLUSIONS}

The limited studies described here suggest that the behaviour of steel frames in a fire can be adequately represented by appropriate subframes similar to those used in conventional structural design. Further studies to refine test details for the present test frame can therefore be conducted on such assemblies, allowing a more comprehensive study in the time available. However, the subframe models chosen must be capable of representing the behaviour of the beams and columns in the zone of interest without introducing unrealistic conditions or restraints. In particular, boundary conditions should be avoided which cause artificial restraint to axial thermal expansion. Only when it is very obvious that beam or column behaviour is going to be dominant should individual elements be considered in isolation. In the context of the frame details considered in this paper, failure has in most cases been precipitated by column yielding. The indicative study for frames with protected columns demonstrates quite different behaviour, and clearly shows the necessity for covering all possibilities in the choice of subframes to be examined. It can be seen that the subframe models, whilst very consistent and reliable in predicting failure temperatures, have been very much less reliable in predicting internal forces, particularly in beams, and should be used with care when these are of importance. It is possible that subframes could even be used as the basis for a manual calculation method for limiting temperatures, although it would be preferable to test a wider range of structure parameters before such methods are established. 
In practical terms one possible design outcome of the current round of studies is a recommendation that columns should in general be fire-protected. The prospect of column failure over more than a very local area of a structure is an unattractive one with potentially disastrous consequences, whereas the failure even of a complete area of unprotected beams is costly but generally less life-threatening. The indicative study of residual effects after cooling offers the prospect, which has not hitherto existed, of a quantitative method for assessment of structural fire damage and the requirements of building repair and reinstatement after a fire.

\section{Acknowledgment}

Development of the analytical principles and software has largely been supported by two successive grants from the Science and Engineering Research Council. The support of British Steel and The Steel Construction Institute is also gratefully acknowledged.

\section{REFERENCES}

1. BS5950: 1985, Structural use of steelwork in building. Part 8: Code of Practice for Fire Resistant Design, BSI, London, 1988.

2. Eurocode 3, Design of steel structures. Part 10: Structural Fire Design (Draft), Commission of the European Communities, 1990.

3. Cunningham, R., 'Some aspects of semi-rigid connections in structural steelwork', The Structural Engineer, 68, No.5/6, (1990), 85-92.

4. Lawson, R.M., 'Behaviour of steel beam-to-column connections in fire', The Structural Engineer, 68, No.14, (1990), 263-271.

5. El-Rimawi, J.A., Burgess, I.W. \& Plank, R.J., 'Modelling the behaviour of steel frames and subframes with semi-rigid connections in fire', Proc. Third CIB/W14 Workshop on Fire Modelling, TNO Rijswijk, 1993, ed. L. Twilt. (in press)

6. El Rimawi, J.A., 'NARR2: A Program for the Structural Analysis of 2-D Frames at Elevated Temperatures', Research Report, University of Sheffield, Department of Civil and Structural Engineering, January 1993.

7. Cooke, G. \& Latham, D., 'The inherent fire resistance of a loaded steel framework', Steel Construction Today, 1, (1987).

8. Franssen, J.-M., Cooke, J.M.E. \& Latham, D., Numerical Simulation of a Full-Scale Fire Test on a Loaded Steel Framework', J. Construct. Steel Research, (in press).

9. Eurocode 4, Design of composite steel and concrete structures. Part 1.2: Structural Fire Design (Draft), Commission of the European Communities, 1992.

10. El-Rimawi, J., Burgess, I.W. and Plank, R.J., 'The analysis of steel beams in fire', Proc. International Conference on Steel and Aluminium Structures, Singapore, 1991, Elsevier, Amsterdam, pp 161-171.

11. BS5950: 1985, Structural use of steelwork in building: Part 1. Code of practice for design in simple and contimuons construction: hot rolled sections, BSI, London, 1985. 